SHORT REPORT

\title{
Is the effect of work stress on cardiovascular mortality confounded by socioeconomic factors in the Valmet study?
}

\author{
E J Brunner, M Kivimäki, J Siegrist, T Theorell, R Luukkonen, H Riihimäki, J Vahtera, J Kirjonen, \\ $P$ Leino-Arjas
}

$\mathrm{T}$ he link between work stress and cardiovascular disease (CVD) is robust, but derived exclusively from observational studies. ${ }^{1}$ The work stress effect may thus not be causal, but attributable to confounding with low socioeconomic position. ${ }^{2}$ This report examines the confounding explanation for the effects of work stress on CVD mortality in the Valmet study, ${ }^{3}$ using measures of socioeconomic circumstances across the life course.

\section{PARTICIPANTS, METHODS, AND RESULTS}

Participants were staff at a metal working company in Finland. The baseline survey (1973) identified those who were free from CVD at baseline (812 employees: 545 men, 267 women) and determined stressful characteristics of work and socioeconomic factors. The questionnaire based evaluation of work stress has been described in detail. ${ }^{3}$ Principal component analysis was used to derive internally consistent scales from existing questionnaire items on work demands, job control, effort at work, and material and psychosocial rewards. Content validity was high compared with the current instruments. Missing values for father's occupation $(\mathrm{n}=14)$ and participant's salary $(\mathrm{n}=40)$ were imputed (SAS PROC MI and PROC MIANALYZE) in relevant analyses using five imputations based on maximum likelihood estimates. The outcome was cardiovascular mortality 1973-2000 from the national mortality register.

One hundred and eighty deaths, of which 73 were from CVD (60 among men), occurred over 27 years of follow up (mean 25.6 years $)$. A third $(\mathrm{n}=24)$ of CVD deaths were among nonmanual employees. Socioeconomic circumstances were associated with both measures of work stress (table 1). Job strain and effort-reward imbalance at baseline were each associated with a doubling of CVD mortality, after adjusting for age and sex (table 2). After excluding non-manual workers, age and sex adjusted hazard ratios for high job strain and high effort-reward imbalance were 1.9 (95\% confidence intervals: 0.7 to 5.1 ) and 2.9 (0.7 to 12.3), respectively.

Of the childhood factors, controlling for education reduced work stress effects slightly $(25 \%-30 \%)$, but controlling for father's occupation and height did not. After simultaneous adjustment for these three childhood factors, the hazard ratio for high job strain was 1.93 ( 1.0 to 3.8 ) and for high effortreward imbalance 2.02 (1.0 to 4.1). Of the adult factors, controlling for occupational group reduced the work stress effects slightly, while adjustment for salary did not. After simultaneous adjustment for occupation and income the hazard ratio for high job strain was 1.95 (0.9 to 4.0) and for high effort-reward imbalance 2.50 (1.1 to 5.8). After

Table 1 Hazard ratios (95\% Cl) for cardiovascular mortality and mean scores of work characteristics by measures of socioeconomic position at baseline in the Valmet study (adjusted for age and sex)

\begin{tabular}{|c|c|c|c|c|}
\hline \multirow[b]{2}{*}{ Confounder } & \multirow{2}{*}{$\begin{array}{l}\text { Number of } \\
\text { participants } \\
\text { (number of } \\
\text { deaths)t }\end{array}$} & \multirow{2}{*}{$\begin{array}{l}\text { CVD mortality } \\
\text { Adjusted HR } \\
(95 \% \mathrm{Cl})\end{array}$} & \multicolumn{2}{|c|}{ Work stress indicators } \\
\hline & & & $\begin{array}{l}\text { Job strain } \\
\text { score }\end{array}$ & $\begin{array}{l}\text { Effort-reward } \\
\text { imbalance score }\end{array}$ \\
\hline \multicolumn{5}{|c|}{ Father's occupational group } \\
\hline White collar & $131(12)$ & 1.00 & $1.8^{*}$ & $1.6^{*}$ \\
\hline Blue collar & $423(37)$ & 1.04 (0.5 to 2.0$)$ & 2.1 & 2.0 \\
\hline Farmer & $244(21)$ & $1.17(0.6$ to 2.4$)$ & 2.1 & 2.3 \\
\hline \multicolumn{5}{|c|}{ Height (cm, men/women) } \\
\hline$>176 />163$ & $275(16)$ & 1.00 & $2.0 \mathrm{NS}$ & $2.0 \mathrm{NS}$ \\
\hline $171-176 / 158-163$ & $267(21)$ & $1.08(0.6$ to 2.1$)$ & 2.1 & 2.1 \\
\hline$<171 /<158$ & $270(36)$ & 1.49 (0.8 to 2.7$)$ & 2.1 & 2.1 \\
\hline \multicolumn{5}{|l|}{ Education } \\
\hline Secondary or more & $77(2)$ & 1.00 & $1.7^{*}$ & $1.2^{*}$ \\
\hline Intermediate level & $409(28)$ & 3.05 (0.7 to 12.9$)$ & 1.9 & 1.8 \\
\hline Primary or less & $326(43)$ & 4.04 (1.0 to 16.8 ) & 2.3 & 2.4 \\
\hline \multicolumn{5}{|l|}{ Occupational group } \\
\hline Managers & $94(5)$ & 1.00 & $1.6^{*}$ & $1.2^{*}$ \\
\hline Other office staff & 269 (19) & $1.29(0.5$ to 3.5$)$ & 1.8 & 1.5 \\
\hline Skilled workers & $165(24)$ & $2.86(1.1$ to 7.5$)$ & 2.2 & 2.4 \\
\hline Semiskilled workers & $284(25)$ & $1.63(0.6$ to 4.3$)$ & 2.4 & 2.6 \\
\hline \multicolumn{5}{|l|}{ Salary } \\
\hline Top quartile & $161(14)$ & 1.00 & $1.7^{*}$ & $1.3^{*}$ \\
\hline $3 \mathrm{rd} / 2 \mathrm{nd}$ & 407 (34) & 1.44 (0.8 to 2.7$)$ & 2.1 & 2.1 \\
\hline Bottom quartile & $204(21)$ & 1.53 (0.8 to 3.0$)$ & 2.3 & 2.4 \\
\hline
\end{tabular}


Table 2 Hazard ratios $(95 \% \mathrm{Cl}$ ) for cardiovascular mortality by levels of work characteristics in the Valmet study (adjusted for age and sex, and separately for measures of socioeconomic position at study baseline)

\begin{tabular}{|c|c|c|c|c|c|c|c|}
\hline & \multirow{2}{*}{$\begin{array}{l}\text { Number of } \\
\text { participants } \\
\text { (number of } \\
\text { deaths) }\end{array}$} & \multirow[b]{2}{*}{$\begin{array}{l}\text { Adjusted for } \\
\text { age and sex }\end{array}$} & \multicolumn{5}{|c|}{ Covariate in addition to age and sex } \\
\hline & & & $\begin{array}{l}\text { Father's occupational } \\
\text { group }\end{array}$ & Height & Education & $\begin{array}{l}\text { Occupational } \\
\text { group }\end{array}$ & Income (salary) \\
\hline \multicolumn{8}{|l|}{ Job strain* } \\
\hline Low & $215(16)$ & 1.00 & 1.00 & 1.00 & 1.00 & 1.00 & 1.00 \\
\hline Intermediate & 389 (32) & $1.53(0.8$ to 2.8$)$ & $1.54(0.8$ to 2.9$)$ & $1.49(0.8$ to 2.7$)$ & $1.39(0.8$ to 2.6$)$ & $1.36(0.7$ to 2.6$)$ & $1.51(0.8$ to 2.9$)$ \\
\hline High & $201(25)$ & 2.20 (1.2 to 4.2$)$ & 2.22 (1.2 to 4.3$)$ & 2.20 (1.2 to 4.2$)$ & 1.85 (1.0 to 3.6$)$ & $1.89(0.9$ to 3.8$)$ & 2.15 (1.1 to 4.4$)$ \\
\hline \multicolumn{8}{|l|}{$\begin{array}{l}\text { Effort-reward } \\
\text { imbalancet }\end{array}$} \\
\hline Low & $269(15)$ & 1.00 & 1.00 & 1.00 & 1.00 & 1.00 & 1.00 \\
\hline Intermediate & $272(29)$ & 2.21 (1.2 to 4.2$)$ & $2.28(1.2$ to 4.4$)$ & 2.09 (1.1 to 4.0$)$ & 1.94 (1.0 to 3.7$)$ & 2.16 (1.0 to 4.5$)$ & 2.35 (1.2 to 4.7$)$ \\
\hline High & $271(29)$ & $2.36(1.3$ to 4.4$)$ & $2.44(1.3$ to 4.7$)$ & 2.29 (1.2 to 4.3$)$ & 2.01 (1.0 to 4.0$)$ & $2.40(1.1$ to 5.5$)$ & 2.56 (1.2 to 5.3$)$ \\
\hline
\end{tabular}

*Low job strain (low demands combined with high or intermediate control), high job strain (high or intermediate demands combined with low control), and intermediate job strain (all other combinations of demands and control). †Tertiles.

controlling for height and all four of the socioeconomic measures, the hazard ratio for high job strain was 2.04 ( 1.0 to 4.3 ) and for effort-reward imbalance 2.54 ( 1.1 to 5.9 ). The corresponding estimates for all cause mortality were $0.95(0.6$ to 1.5$)$ and 1.08 (0.7 to 1.8 ) respectively. The association between effort-reward imbalance and non-CVD mortality was non-significant, but, unexpectedly, high job strain was related to lowered non-CVD mortality (hazard ratio 0.51 (0.3 to 1.0$)$ ).

\section{COMMENT}

This study shows that work stress was a robust predictor of cardiovascular mortality after controlling for socioeconomic circumstances in childhood and adulthood, adding evidence that stress may be causally related to risk of CVD. ${ }^{1}$ Reporting bias is most unlikely to account for our findings. The outcome was CVD mortality obtained from the reliable Finnish national register. There was a comparatively long follow up period of 27 years and so sub-clinical disease is unlikely to lie behind reports of high work stress. Indeed, exposure was measured once and therefore the effects observed may be underestimated. Work circumstances seem quite stable in this cohort. Of the 674 participants in the five year follow up, $87 \%$ remained in the same occupational group as at baseline. At 10 years the most common reason for change in employment status was retirement. At the end of follow up (2000) 53\% reported Valmet as their current or last employer.

Most but not all of previously published prospective studies of work stress and CVD show a similar relation to that published here. ${ }^{1}$ However, several of these were not able to take adequate account of socioeconomic circumstances, as we have done. The effect of job strain on CVD risk may be limited to those on low incomes in some populations, ${ }^{4}$ but in the Whitehall II cohort, for example, the effect tended if anything to be greater in higher civil service grades..$^{5}$ In our study, salary was the purest available measure of current material circumstances and controlling for it did not weaken the effects of workplace stress.

Educational attainment is a predictor of future income and psychosocial resources, and was linked both to work stress exposures and to CVD risk in this study. In models that included both education and work stress, work stress was the stronger predictor of mortality, and may thus lie on the pathway between education and CVD.

In conclusion, the Valmet study provides evidence for a link between work stress and mortality with cardiovascular causes. This effect does not seem to be explained entirely by confounding by socioeconomic circumstances over the life course. Further studies are needed to assess the generalisability and specificity of our findings and to link the epidemiological evidence with the physiological and behavioural mechanisms that may underlie the effects of work stress on cardiovascular disease. ${ }^{6}$

\section{ACKNOWLEDGEMENTS}

We gratefully acknowledge the role of Professors Jeddi Hasan and Risto Telama in founding the Valmet cohort, and the financial support of the Academy of Finland (projects 70139, 77560, and 105195) during successive phases of the study programme.

\section{Authors' affiliations}

E J Bruner, International Centre for Health and Society, Department of Epidemiology and Public Health, University College London, UK M Kivimäki, Department of Psychology, University of Helsinki, Helsinki, Finland

J Siegrist, Department of Medical Sociology, University of Duesseldorf, Duesseldorf, Germany

T Theorell, Department of Public Health Sciences, Karolinska Institutet and National Institute for Psychosocial Factors and Health, Stockholm, Sweden

R Luukkonen, H Riihimäki, P Leino-Arjas, Department of Epidemiology and Biostatistics, Finnish Institute of Occupational Health, Helsinki, Finland

J Vahtera, Turku Regional Institute of Occupational Health, Turku, Finland

J Kirionen, University of Jyväskylä, Finland

Conflicts of interest: none declared.

Correspondence to: Dr E J Brunner, International Centre for Health and Society, Department of Epidemiology and Public Health, University College London, 1-19 Torrington Place, London WC1E 6BT, UK; e.brunner@ucl.ac.uk

Accepted for publication 22 March 2004

\section{REFERENCES}

1 Kuper $\mathrm{H}$, Marmot $M$, Hemingway $\mathrm{H}$. Systematic review of prospective cohort studies of psychosocial factors in the etiology and prognosis of coronary heart disease. Semin Vasc Med 2002;2:267-314.

2 Macleod J, Davey Smith G, Heslop P, et al. Are the effects of psychosocial exposures attributable to confounding? Evidence from a prospective observational study on psychological stress and mortality. J Epidemiol Community Health 2001;55:878-84.

3 Kivimäki $M$, Leino-Arjas $P$, Luukkonen $R$, et al. Work stress and risk of cardiovascular mortality: prospective cohort study of industrial employees. BMJ 2002;325:857-60.

4 Lynch J, Krause N, Kaplan GA, et al. Workplace conditions, socioeconomic status, and the risk of mortality and acute myocardial infarction: the Kuopio ischaemic heart disease risk factor study. Am J Public Health 1997;87:617-22

5 Kuper H, Marmot M. Job strain, job demands, decision latitude, and the risk of coronary heart disease within the Whitehall II study. J Epidemiol Community Health 2003:57: 147-53.

6 Brunner EJ. Stress mechanisms in coronary heart disease. In: Stansfeld SA, Marmot MG, eds. Stress and the heart: psychosocial pathways to coronary heart disease. London: BMJ Books, 2002:181-99. 